\title{
Terbocenium: completing a heavy lanthanide metallocenium cation family with an alternative anion abstraction strategy
}

DOI:

10.1039/C8CC05261A

\section{Document Version}

Accepted author manuscript

Link to publication record in Manchester Research Explorer

\section{Citation for published version (APA):}

Goodwin, C., Reta, D., Ortu, F., Liu, J., Chilton, N., \& Mills, D. (2018). Terbocenium: completing a heavy lanthanide metallocenium cation family with an alternative anion abstraction strategy. Chemical Communications, 54(66), 9182-9185. https://doi.org/10.1039/C8CC05261A

\section{Published in:}

Chemical Communications

\section{Citing this paper}

Please note that where the full-text provided on Manchester Research Explorer is the Author Accepted Manuscript or Proof version this may differ from the final Published version. If citing, it is advised that you check and use the publisher's definitive version.

\section{General rights}

Copyright and moral rights for the publications made accessible in the Research Explorer are retained by the authors and/or other copyright owners and it is a condition of accessing publications that users recognise and abide by the legal requirements associated with these rights.

\section{Takedown policy}

If you believe that this document breaches copyright please refer to the University of Manchester's Takedown Procedures [http://man.ac.uk/04Y6Bo] or contact uml.scholarlycommunications@manchester.ac.uk providing relevant details, so we can investigate your claim.

\section{OPEN ACCESS}




\section{Terbocenium: completing a heavy lanthanide metallocenium cation family with an alternative anion abstraction strategy ${ }^{\dagger}$}

Received 00th January 20xx Accepted 00th January 20xx

DOI: $10.1039 / x 0 x \times 00000 x$
Conrad A. P. Goodwin, Daniel Reta, Fabrizio Ortu, Jingjing Liu, Nicholas F. Chilton* and David P. Mills*

www.rsc.org/

A series of heavy lanthanide metallocenium cations $\left[\operatorname{Ln}\left(\mathrm{Cp}^{\mathrm{ttt}}\right)_{2}\right]^{+}$

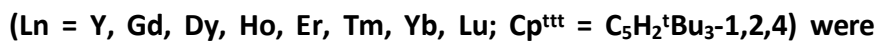
recently prepared by halide abstraction of $\left[\operatorname{Ln}\left(\mathrm{Cp}^{\mathrm{ttt}}\right)_{2}(\mathrm{Cl})\right]$, but curiously the $\mathrm{Tb}$ analogues remained elusive. Here we report an alternative anion abstraction strategy to access $\left[\mathrm{Tb}\left(\mathrm{Cp}^{\mathrm{ttt}}\right)_{2}\right]^{+}$, completing the heavy $\left[\operatorname{Ln}\left(\mathrm{Cp}^{\mathrm{ttt}}\right)_{2}\right]^{+}$family.

Single-molecule magnets (SMMs) have potential for highdensity data storage, but all examples to date only show magnetic hysteresis with expensive liquid helium cooling. ${ }^{1}$ Significant research effort has concentrated on achieving SMMs that operate under cheaper liquid nitrogen temperature regimes $(>77 \mathrm{~K})$, and lanthanide (Ln) systems are widely considered to be the most promising candidates to realise this goal. ${ }^{2}$ Since the first Ln SMM was reported in $2003,{ }^{3}$ systems containing $\mathrm{Tb}^{3+}$ ions held record magnetic hysteresis temperatures up to $14 \mathrm{~K} .{ }^{4}$ However, these landmark examples were recently superseded by the dysprosocenium complex $\left[\mathrm{Dy}\left(\mathrm{Cp}^{\mathrm{ttt}}\right)_{2}\right]\left[\mathrm{B}\left(\mathrm{C}_{6} \mathrm{~F}_{5}\right)_{4}\right] \quad\left(\mathrm{Cp}^{\mathrm{ttt}}=\mathrm{C}_{5} \mathrm{H}_{2} \mathrm{BB}_{3}-1,2,4\right)$, which exhibits magnetic bistability up to $60 \mathrm{~K} \cdot{ }^{5}$ Previous efforts to synthesise isolated Ln metallocenium cations were thwarted by the tendency for large $\mathrm{Ln}^{3+}$ cations to exhibit equatorial interactions with counterions. ${ }^{6}$ The combination of two bulky $\mathrm{Cp}^{\mathrm{ttt}}$ ligands and the weakly coordinating anion $\left[\mathrm{B}\left(\mathrm{C}_{6} \mathrm{~F}_{5}\right)_{4}\right]^{-}$was found to be sufficient to prevent such interactions in $\left[\mathrm{Dy}\left(\mathrm{Cp}^{\mathrm{ttt}}\right)_{2}\right]^{+}$, providing it with enhanced magnetic properties over closely related $\left[\mathrm{Dy}\left(\mathrm{Cp}^{*}\right)_{2}\left\{\mu-(\mathrm{Ph})_{2} \mathrm{BPh}_{2}\right\}\right]\left(\mathrm{Cp}^{*}=\mathrm{C}_{5} \mathrm{Me}_{5}\right) .^{7}$

Prior to the report of $\left[\mathrm{Dy}\left(\mathrm{Cp}^{\mathrm{ttt}}\right)_{2}\right]^{+}$, the synthetic community were guided by design criteria to develop improved $\mathrm{Ln}$ SMMs: ${ }^{8,9}$ for $\mathrm{Ln}^{3+}$ ions whose most magnetic $m$, projections have oblate-spheroidal electron densities (such as $\mathrm{Tb}^{3+}$ and $\left.\mathrm{Dy}^{3+}\right)$, axial ligand fields were predicted to increase the effective barrier to magnetisation reversal $\left(U_{\text {eff }}\right)$. Following

School of Chemistry, The University of Manchester, Oxford Road, Manchester, M13 9PL,UK.Email: david.mills@manchester.ac.uk; nicholas.chilton@manchester.ac.uk.

†Electronic Supplementary Information (ESI) available: Full synthetic details, crystallography, UV/Vis/NIR, NMR, FTIR, and EPR spectra, magnetism and ab initio calculations. CCDC 1844350-1844354. For ESI and crystallographic data in CIF or other electronic format see DOI: $10.1039 / x 0 x \times 00000 x$ these strategies record $U_{\text {eff }}$ values were achieved for $\mathrm{Dy}^{3+}$ SMMs, but these molecules did not exhibit magnetic hysteresis at higher values than $\mathrm{Tb}^{3+}$ systems that preceded them. ${ }^{10-13}$

We recently showed that the slow magnetic relaxation of $\left[\mathrm{Dy}\left(\mathrm{Cp}^{\mathrm{ttt}}\right)_{2}\right]^{+}$is due to the constrained metal-ligand vibrational modes of the bis- $\mathrm{Cp}^{\text {ttt }}$ framework; ${ }^{5 a}$ to further rationalise these remarkable magnetic properties we synthesised a series of structurally analogous heavy $\mathrm{Ln}$ metallocenium complexes, $\left[\mathrm{Ln}\left(\mathrm{Cp}^{\mathrm{ttt}}\right)_{2}\right]\left[\mathrm{B}\left(\mathrm{C}_{6} \mathrm{~F}_{5}\right)_{4}\right](\mathrm{Ln}=\mathrm{Y}, \mathrm{Gd}, \mathrm{Ho}, \mathrm{Er}, \mathrm{Tm}, \mathrm{Yb}, \mathrm{Lu})$ by halide abstraction of the parent $\left[\mathrm{Ln}\left(\mathrm{Cp}^{\mathrm{ttt}}\right)_{2}(\mathrm{Cl})\right] \cdot{ }^{5 a, 14}$ Analysis of the magnetic relaxation mechanisms of these systems revealed that anomalously low Raman exponents are a defining feature of $\left[\mathrm{Ln}\left(\mathrm{Cp}^{\mathrm{ttt}}\right)_{2}\right]^{+}$cations, and these return to 'normal' values when $\mathrm{Cl}^{-}$anions bind to the $\mathrm{Ln}^{3+}$ ions. ${ }^{14}$ Frustratingly, we were unable to access the homologous $\mathrm{Tb}^{3+}$ cation $\left[\mathrm{Tb}\left(\mathrm{Cp}^{\mathrm{ttt}}\right)_{2}\right]^{+}$, as the attempted synthesis of the precursor $\left[\mathrm{Tb}\left(\mathrm{Cp}^{\mathrm{ttt}}\right)_{2}(\mathrm{Cl})\right]$ from $\mathrm{TbCl}_{3}$ and two equivalents of $\mathrm{KCp}^{\mathrm{ttt}}$ consistently gave oily residues containing $\mathrm{Cp}^{\mathrm{ttt} H} .{ }^{14}$ The previous successes of $\mathrm{Tb}^{3+}$ SMMs made this omission significant, as we wished to compare the effects of the bis- $\mathrm{Cp}^{\mathrm{ttt}}$ ligand environment on the magnetic properties of the Kramers ion Dy ${ }^{3+}\left({ }^{6} \mathrm{H}_{15 / 2}\right)$ with its neighbouring non-Kramers ion $\mathrm{Tb}^{3+}\left({ }^{7} \mathrm{~F}_{6}\right)$.

To address this impasse we prepared $\left[\mathrm{Ln}\left(\mathrm{BH}_{4}\right)_{3}(\mathrm{THF})_{3}\right]$ (1$\mathrm{Ln}$; $\mathrm{Ln}=\mathrm{Tb}, \mathrm{Y}$ ) from the parent $\mathrm{Lnl}_{3}$ and a large excess of $\mathrm{KBH}_{4}$ in THF by adapting literature procedures; ${ }^{15,16}$ diamagnetic $\mathrm{Y}^{3+}$ surrogates allow analogous complexes to be studied by NMR spectroscopy (Scheme 1). Treatment of 1-Ln with two equivalents of $\mathrm{KC} \mathrm{p}^{\mathrm{ttt}} 17$ gave $\left[\mathrm{Ln}\left(\mathrm{Cp}^{\mathrm{ttt}}\right)_{2}\left(\mathrm{BH}_{4}\right)\right](\mathbf{2}-\mathrm{Ln} ; \mathrm{Ln}=\mathrm{Tb}, \mathrm{Y})$ by salt metathesis, in common with the related syntheses of $\left[\mathrm{Ln}\left(\mathrm{Cp}^{\mathrm{ttt}}\right)_{2}\left(\mathrm{BH}_{4}\right)\right]\left(\mathrm{Ln}=\mathrm{La}^{16} \mathrm{Tm}^{18}\right)$. Gratifyingly, the separate reactions of 2-Ln with $\left[\mathrm{Ph}_{3} \mathrm{C}\right]\left[\mathrm{B}\left(\mathrm{C}_{6} \mathrm{~F}_{5}\right)_{4}\right]^{19}$ in benzene gave the terbocenium complex $\left[\mathrm{Tb}\left(\mathrm{Cp}^{\mathrm{ttt}}\right)_{2}\right]\left[\mathrm{B}\left(\mathrm{C}_{6} \mathrm{~F}_{5}\right)_{4}\right]$ (3-Tb) and the previously reported $\mathrm{Y}$ analogue $3-\mathrm{Y} .^{\text {5a }}$ The borohydride anion acts as a masked hydride to give $\mathrm{Ph}_{3} \mathrm{CH}$, with an entropic driving force provided by the formation of half an equivalent of gaseous diborane. In agreement with previous studies, ${ }^{14}$ we found that samples of 3-Ln recrystallised from DCM layered with hexane decompose rapidly at room temperature, thus these were stored and manipulated at $-25^{\circ} \mathrm{C}$. 


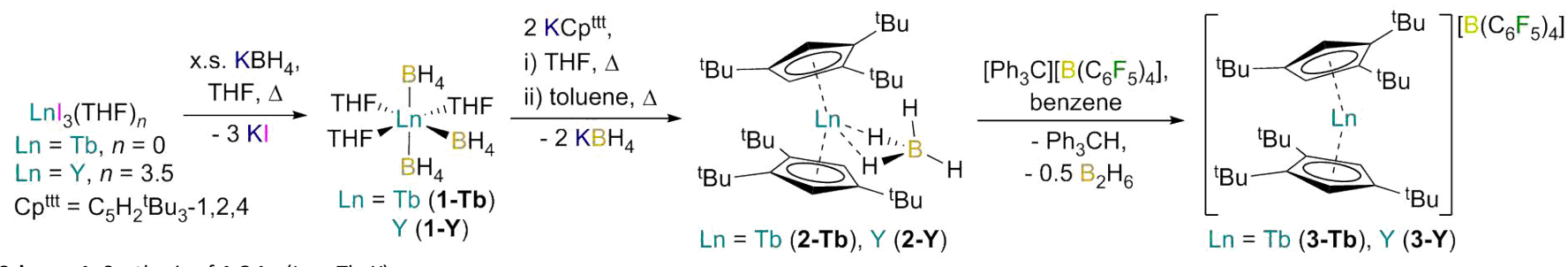

Scheme 1. Synthesis of 1-3- $\operatorname{Ln}(\operatorname{Ln}=\mathrm{Tb}, \mathrm{Y})$.

The analytical data obtained for 3-Tb are consistent with homologous complexes; $5,14,16,18,20$ the data for 2-Ln are similar to $\left[\mathrm{Ln}\left(\mathrm{Cp}^{\mathrm{ttt}}\right)_{2}\left(\mathrm{BH}_{4}\right)\right]\left(\mathrm{Ln}=\mathrm{La},{ }^{16} \mathrm{Dy}^{20}\right)$, and the characterisation data for 3-Y has been reported previously. ${ }^{5 a}$ In common with the synthesis of $\left[\mathrm{La}\left(\mathrm{BH}_{4}\right)_{3}(\mathrm{THF})_{4}\right]$ from Lal ${ }_{3},{ }^{16}$ microanalysis and single crystal XRD data indicated that 1-Ln contained iodide impurities $(<15 \%)$, but these could not be detected in 2-Ln. The paramagnetism of $\mathbf{3}-\mathbf{T b}$ precluded assignment of its ${ }^{1} \mathrm{H}$ and ${ }^{13} \mathrm{C}\left\{{ }^{1} \mathrm{H}\right\}$ NMR spectra, as previously reported for $\mathbf{3}-\mathbf{G d} .{ }^{14}$ However, paramagnetically shifted signals for $\left[B\left(C_{6} F_{5}\right)_{4}\right]^{-}$ anions were seen in the ${ }^{11} \mathrm{~B}(-27.49 \mathrm{ppm})$ and ${ }^{19} \mathrm{~F}$ (meta: -182.42 , para: -172.46 , ortho: $-144.60 \mathrm{ppm}$ ) NMR spectra of 3-Tb; similar shifts were seen for the 3 -Ln series. ${ }^{14}$ The ${ }^{11} \mathrm{~B}$ NMR spectrum of 2-Tb was featureless, but paramagnetically shifted tBu group signals were seen in the ${ }^{1} \mathrm{H}$ NMR spectrum.

The solid state structures of 1-3-Ln were determined by single crystal XRD (see Figs. 1 and 2 for the structures of 2-Tb and the cation of $\mathbf{3}-\mathbf{T b} \cdot \mathbf{C H}_{\mathbf{2}} \mathbf{C l}_{\mathbf{2}}$, see ESI for other structures; 1$\mathbf{Y}^{21}$ and 3-Y5a have been reported previously but we obtained a new dataset for 1-Y). Complex 1-Tb is structurally analogous to 1-Y, with a pseudo-distorted octahedral structure and a meridional arrangement of ligands. As expected, the larger $\mathrm{Tb}^{3+}$ centre (six-coordinate ionic radii, $\mathrm{pm}: \mathrm{Tb}^{3+}, 0.923 ; \mathrm{Y}^{3+}$, $0.900)^{22}$ causes $\mathbf{1}-\mathbf{T b}$ to exhibit longer bond distances than 1-Y. The same trends are seen for $\mathbf{2}-\mathbf{Y}$ and $\mathbf{2}-\mathbf{T b}$, which are disordered over two sites but are isostructural with the $\mathrm{Dy}^{3+}$ congener: the mean $\mathrm{Tb} \cdots C \mathrm{p}_{\text {centroid }}$ distance $(2.418(3) \AA)$ and the $C p_{\text {centroid }} \cdots \mathrm{Tb} \cdots C p_{\text {centroid }}$ angle $\left(148.13(5)^{\circ}\right)$ in 2-Tb are similar to the corresponding metrical parameters in $\left[\mathrm{Dy}\left(\mathrm{Cp}^{\mathrm{ttt}}\right)_{2}\left(\mathrm{BH}_{4}\right)\right]$ $\left(2.394(2) \AA\right.$ and $\left.149.01(6)^{\circ}\right) .{ }^{20}$ Complex 3-Tb has a shorter

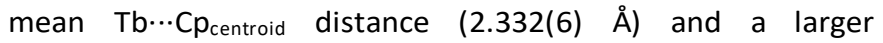
$\mathrm{Cp}_{\text {centroid }} \cdots \mathrm{Tb} \cdots \mathrm{C} \mathrm{p}_{\text {centroid }}$ angle $\left(152.2(2)^{\circ}\right)$ than for 2-Tb. The $\left[\mathrm{Tb}\left(\mathrm{Cp}^{\mathrm{ttt}}\right)_{2}\right]^{+}$cation of $\mathbf{3}-\mathrm{Tb}$ is best compared with the $\mathrm{Dy}^{3+}$ homologue 3-Dy, which exhibits a $C \mathrm{Cp}_{\text {centroid }} \cdots \mathrm{Dy} \cdot \mathrm{Cp}_{\text {centroid }}$ angle of $152.56(7)^{\circ}$ and a mean Dy $\cdots C p_{\text {centroid }}$ distance of $2.316(3) \AA . .^{5}$ Most importantly there are no equatorial interactions seen between the $\left[B\left(\mathrm{C}_{6} \mathrm{~F}_{5}\right)_{4}\right]^{-}$anion and the $\mathrm{Tb}^{3+}$ centre of 3-Tb in the solid state [closest Tb...F distance: $6.336(6) \AA$ ] , hence the bis-C $\mathrm{p}^{\text {ttt }}$ framework can be considered to be the sole contributor to crystal field (CF) splittings in 3-Tb.

The magnetic susceptibility temperature products $\left(\chi_{M} T\right)$ of 2-Tb $\left(10.84 \mathrm{~cm}^{3} \mathrm{~K} \mathrm{~mol}^{-1}\right.$ at $\left.300 \mathrm{~K}\right)$ and 3-Tb $\left(11.60 \mathrm{~cm}^{3} \mathrm{~K} \mathrm{~mol}^{-1}\right.$ at $260 \mathrm{~K})$ were obtained for polycrystalline samples with SQUID magnetometry (Table S3). The high temperature values are lower than the free-ion Curie value for $\mathrm{Tb}^{3+}\left(11.82 \mathrm{~cm}^{3} \mathrm{~K}\right.$ $\left.\mathrm{mol}^{-1}\right),{ }^{6}$ but are similar to that previously reported for $\left[\mathrm{Tb}(\mathrm{Cp})_{2}\left\{\mu-(\mathrm{Ph})_{2} \mathrm{BPh}_{2}\right\}\right]\left(10.64 \mathrm{~cm}^{3} \mathrm{~K} \mathrm{~mol}^{-1}\right) .{ }^{7 b}$ The $\chi_{M} T$ values for 2-Tb and 3-Tb (Fig. S25) show a gradual decrease with

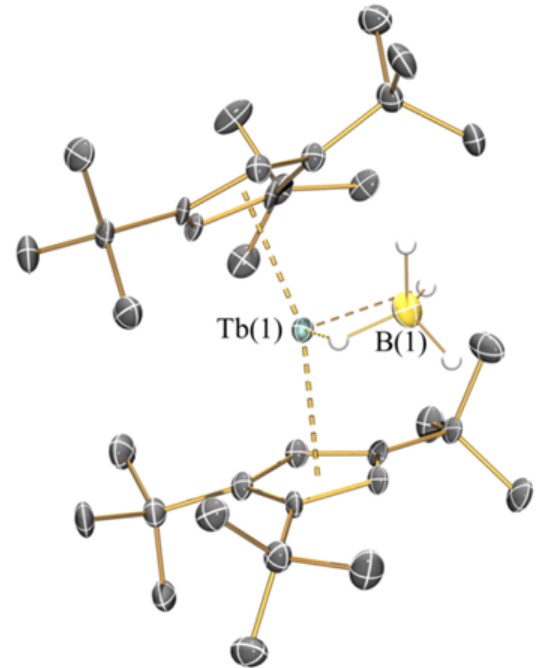

Fig. 1. Molecular structure of $\left[\mathrm{Tb}\left(\mathrm{Cp}^{\mathrm{ttt}}\right)_{2}\left(\mathrm{BH}_{4}\right)\right]$ (2-Tb) with selective atom labelling. Displacement ellipsoids set at $30 \%$ probability level and hydrogen atoms apart from those on $B$ are omitted for clarity. Selected distances and

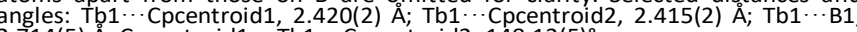
714(5) $\AA$; Cpcentroid1 ‥Tb1… Cpcentroid2, 148.13(5) ${ }^{\circ}$

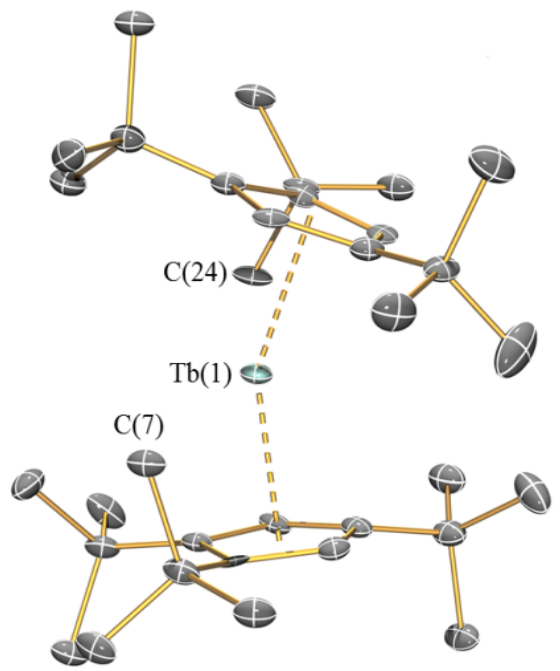

Fig. 2. Molecular structure of the cation of $\left[\mathrm{Tb}\left(\mathrm{Cp}^{\mathrm{ttt}}\right)_{2}\right]\left[\mathrm{B}\left(\mathrm{C}_{6} \mathrm{~F}_{5}\right)_{4}\right] \cdot \mathrm{CH}_{2} \mathrm{Cl}_{2}$ Tb. $\mathrm{CH}_{2} \mathrm{Cl}_{2}$ ) with selective atom labelling. Displacement ellipsoids set at $30 \%$ probability level and hydrogen atoms, lattice solvent and anion are omitted for clarity. Selected distances and angles: Tb1 … Cpcentroid1, 2.325(4) Tb1 $\cdots H, 2.5379(5)$ and $2.5097(5) \AA$ A C Cpcentroid1 1 . Tb1 $\cdots$ Cpcentroid2, $152.2(2)^{\circ}$.

temperature due to depopulation of excited $\mathrm{CF}$ states, reaching 9.30 and $9.06 \mathrm{~cm}^{3} \mathrm{~mol}^{-1} \mathrm{~K}$ for 2-Tb $(5 \mathrm{~K})$ and 3-Tb (2 $\mathrm{K})$, respectively. All experimental $\chi_{M} T$ values are close to those predicted by CASSCF-SO calculations, with minor discrepancies attributed to uncertainties in the diamagnetic corrections (Fig. S25). The low temperature magnetisation isotherms of 2-Tb and 3-Tb (Fig. S26) are in good agreement with calculated values, indicating that the calculations have captured the ground state wavefunctions accurately. 
a)

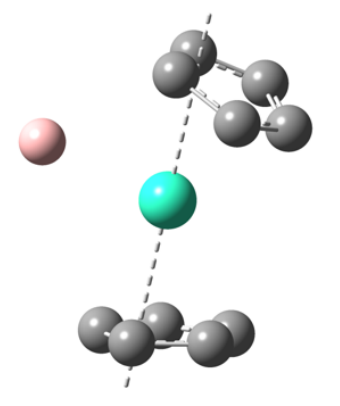

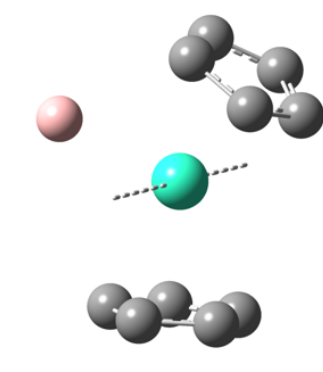

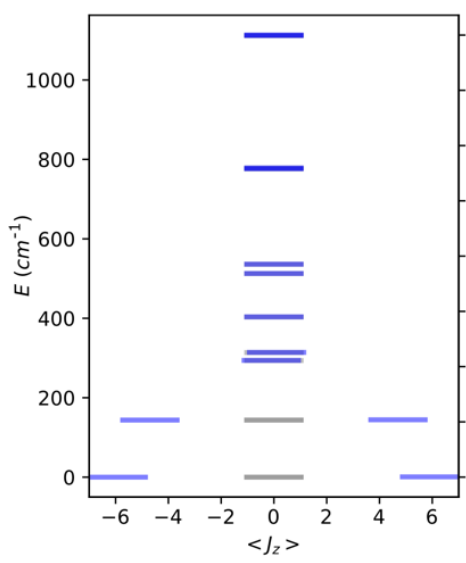

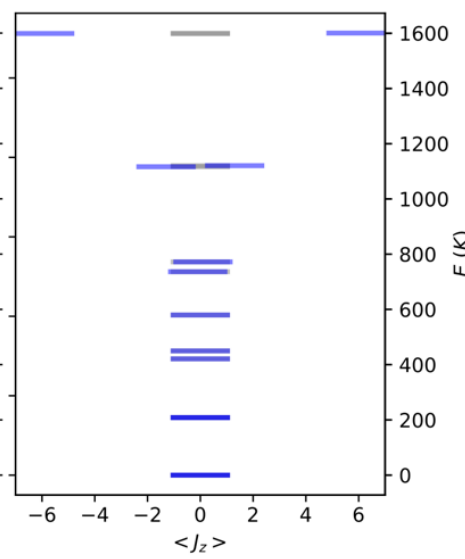

b)
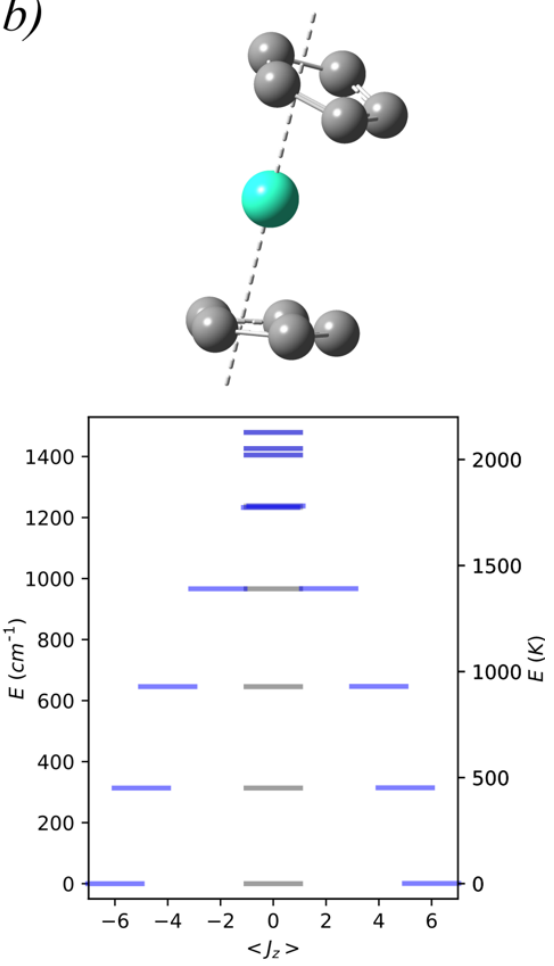

Fig 3. Electronic structure of (a) 2-Tb and (b) 3-Tb, calculated with CASSCF-SO. Grey and blue lines are electronic states under zero and an $0.1 \mathrm{~T}$ field applied along the quantization axis (dashed rod), respectively. (a, left) Quantisation axis is defined along $g_{3}$ of the ground pseudo-doublet; (a, right; b) quantisation axis is explained in the main text. $\mathrm{Bu}$ groups and $\mathrm{H}$ atoms omitted for clarity. $\left\langle J_{z}\right\rangle$ is the expectation value of $J_{z}$ and is proportional to the magnetic moment.

Given the remarkable hysteretic properties of the $\left[\mathrm{Dy}\left(\mathrm{Cp}^{\mathrm{ttt}}\right)_{2}\right]^{+}$cation in 3-Dy, ${ }^{5}$ we studied the magnetisation dynamics of 2-Tb and 3-Tb. Complex 2-Tb shows no out-ofphase signal in AC susceptibility measurements in zero field, however it shows signs of temperature dependent slow magnetic relaxation under an applied field of $0.1 \mathrm{~T}$ (Figs. S27 and S28). The relaxation rates are markedly temperaturedependent above ca. $6 \mathrm{~K}$, however they approach a temperature-independent regime at lower temperatures, suggestive of quantum tunnelling of the magnetisation (QTM) with $\tau_{\text {QTM }} \sim 0.9 \times 10^{-4} \mathrm{~s}$ (Fig. S29, Table S5). The data $>6 \mathrm{~K}$ can be modelled with either a power-law or an exponential temperature dependence (Table S5), however the exponential model suggests $U_{\text {eff }}=29 \mathrm{~cm}^{-1}$, which our CASSCF-SO calculations rule out (see below). Therefore, we believe the thermally-activated relaxation to be a Raman-like process with $C=0.26 \mathrm{~s}^{-1} \mathrm{~K}^{-n}$ and $n=4.6$. Compound 3-Tb on the other hand shows slow magnetic relaxation in zero magnetic field (Figs. S30 and S31), where the temperature dependence of the relaxation rate displays power-law behaviour with coefficients $C=24 \mathrm{~s}^{-1} \mathrm{~K}^{-n}$ and $n=1.2$ (Fig. S32, Table S7). The $n$ values for 2Tb and 3-Tb are quite reduced from the value of $n=7$ traditionally expected for Raman relaxation in non-Kramers compounds, ${ }^{23}$ however the values for 3-Tb are similar to those for the related $\left[\mathrm{Ho}\left(\mathrm{Cp}^{\mathrm{ttt}}\right)_{2}\right]^{+}$cation in 3-Ho, which has $C=3.4 \mathrm{~s}^{-1}$ $\mathrm{K}^{-\mathrm{n}}$ and $n=2.9 .{ }^{14}$ Indeed, we observe the same trend between 2-Tb/3-Tb here as for the $\left[\operatorname{Ln}\left(\mathrm{Cp}^{\mathrm{ttt}}\right)_{2} \mathrm{Cl}\right] /\left[\operatorname{Ln}\left(\mathrm{Cp}^{\mathrm{ttt}}\right)_{2}\right]^{+}$pairs, where the Raman exponent is much lower for the isolated metallocenium cation than for the neutral contact ion pair, ${ }^{14}$ again suggesting that low Raman exponents are characteristic of the bis-Cptt framework. While a power-law temperature dependence with $n=1$ is expected for the Direct relaxation process, ${ }^{23}$ CASSCF-SO calculations (see below) suggest that 3Tb has a near-degenerate pseudo-doublet ground state, rendering Direct relaxation ineffective at zero magnetic field. However, despite the observation of slow magnetic relaxation in zero field, there is no significant opening of the magnetic hysteresis even at $2 \mathrm{~K}$ for 3-Tb (Fig. S33). Field-cooled/zerofield-cooled susceptibility experiments show that while there is bifurcation below $20 \mathrm{~K}$, and thus some slow relaxation, there is no clear maximum $>2 \mathrm{~K}$, suggesting the absence of magnetic blocking (Fig. S34). We note that the SMM properties for 3-Tb appear to be markedly worse than the related complex $\left[\mathrm{Tb}\left(\mathrm{Cp}^{*}\right)_{2}\left\{\mu-(\mathrm{Ph})_{2} \mathrm{BPh}_{2}\right\}\right]$ which shows Orbach-type relaxation with an effective barrier to magnetisation reversal of $U_{\text {eff }}=221$ $\mathrm{cm}^{-1}{ }^{7 \mathrm{~b}}$ However, those data were collected under a $0.24 \mathrm{~T}$ applied field and the magnetic relaxation of $\left[\mathrm{Tb}(C \mathrm{Cp} *)_{2}\{\mu\right.$ $\left.\left.(\mathrm{Ph})_{2} \mathrm{BPh}_{2}\right\}\right]$ in zero field is actually $20-60$ times faster than 3Tb under the same conditions; notably, $\left[\mathrm{Tb}\left(\mathrm{Cp}^{*}\right)_{2}\left\{\mu-(\mathrm{Ph})_{2} \mathrm{BPh}_{2}\right\}\right]$ also does not show open magnetic hysteresis. ${ }^{7 b}$

The lack of a barrier to magnetisation reversal and hysteresis for 3-Tb compared to 3-Dy was unexpected, thus we determined the electronic structures of 2-Tb and 3-Tb with complete active space self-consistent field spin-orbit (CASSCFSO) calculations using MOLCAS $8.0^{24}$ (Fig. 3, see ESI for full details). For 2-Tb we find a highly axial ground pseudo-doublet with the main $g$-value approaching that for the $m_{\lrcorner}= \pm 6$ state (Tables S8 and S9). Along with the first excited state (dominated by $m_{\lrcorner}= \pm 5$ ), the ground pseudo-doublet is quantised along the $\mathrm{Cp}^{\mathrm{ttt}}-\mathrm{Tb}-\mathrm{Cp}^{\mathrm{ttt}}$ direction (Fig. 3a left) suggesting that the $\mathrm{CF}$ imposed by the $\mathrm{BH}_{4}{ }^{-}$anion is much weaker than that of the $\mathrm{Cp}^{\text {ttt }}$ ligands. However, the most 
excited states of the multiplet correspond to a pseudo-doublet that resembles the $m_{\jmath}= \pm 6$ state quantised along the vector normal to the plane of $\mathrm{Cp}^{\text {ttt }}$-B-Cp ${ }^{\text {ttt }}$ (Fig. 3a right, Tables S10 and S11): a similar situation was observed for $\left[\mathrm{Ln}\left(\mathrm{Cp}^{\mathrm{ttt}}\right)_{2}(\mathrm{Cl})\right],{ }^{14}$ which is the hallmark of anisotropic ions in low-symmetry environments. ${ }^{25}$ In common with 2-Tb, 3-Tb has a highly axial ground pseudo-doublet, however in this case the five lowest lying pseudo-doublets are well described as $m_{\lrcorner}= \pm 6, \pm 5, \pm 4, \pm 3$ and \pm 2 quantised along the $C \mathrm{p}^{\mathrm{ttt}}-\mathrm{Tb}-\mathrm{Cp} \mathrm{p}^{\mathrm{ttt}}$ direction (Fig. $3 \mathrm{~b}$, Tables S12 and S13). In this case, we clearly observe a singlet most-excited state which corresponds to $m_{J}=0$ : this indicates a higher degree of uniaxiality in the electronic structure of 3Tb compared to 2-Tb.

For 2-Tb and 3-Tb under zero applied magnetic field, the ground state pseudo-doublet is mixed between the $m_{\lrcorner}=+6$ and the $m_{J}=-6$ states. For 2-Tb this causes a tunnelling gap of ca. $0.03 \mathrm{~cm}^{-1}$, explaining the lack of slow relaxation in zero magnetic field, while the tunnelling gap for 3-Tb is much smaller $\left(<10^{-3} \mathrm{~cm}^{-1}\right)$ thus slow relaxation is observed under zero magnetic field. However, QTM is likely enhanced by transverse dipolar fields in the solid state, as observed for $\left[\mathrm{Tb}(\mathrm{Cp} *)_{2}\left\{\mu-(\mathrm{Ph})_{2} \mathrm{BPh}_{2}\right\}\right],{ }^{7 b}$ and is clearly sufficient to preclude open hysteresis in either compound. Therefore, the differences between 3-Tb and 3-Dy can be attributed to the non-Kramers nature of the former vs. the Kramers nature of the latter: the ground $m_{\text {J }}$ doublet of $\mathrm{Dy}^{3+}$ is resistant to direct mixing between the two projections, whereas there is no such restriction for $\mathrm{Tb}^{3+}$, thus efficient relaxation by QTM is facilitated in low symmetry environments. ${ }^{1,26}$ Although the bis$\mathrm{Cp}^{\mathrm{ttt}}$ framework engenders large magnetic anisotropy in 3-Tb, it is apparent that high-symmetry environments are a requirement to prevent mixing between the opposing projections of the non-Kramers pseudo-doublets of $\mathrm{Tb}^{3+}$ ions, unlike for $\mathrm{Dy}^{3+}$ ions. Therefore, future strategies to achieve high temperature magnetic hysteresis in monometallic $\mathrm{Tb}^{3+}$ SMMs may require symmetry-protection of the ground state by appropriate ligand design. ${ }^{26}$

This work was supported by the EPSRC (Doctoral Prize Fellowship to C.A.P.G., EP/P002560/1 for D.R. and F.O.), the Ramsay Memorial Trust (fellowship to N.F.C.) and the University of Manchester. We thank the EPSRC UK National Electron Paramagnetic Resonance Service for access to the EPR facility and the SQUID magnetometer, and the University of Manchester for access to the Computational Shared Facility. We thank Prof. R. E. P. Winpenny for helpful discussions. Research data files supporting this publication are available from Mendeley Data at doi:10.17632/ybzffm28mf.1.

\section{Conflicts of interest}

There are no conflicts to declare.

\section{Notes and references}

1 D. Gatteschi, R. Sessoli and J. Villain, Molecular Nanomagnets, Oxford University Press, 2006.
2 R. A. Layfield and M. Murugesu, Lanthanides and Actinides in Molecular Magnetism, Wiley-VCH, 2015.

3 N. Ishikawa, M. Sugita, T. Ishikawa, S. Koshihara and Y. Kaizu, J. Am. Chem. Soc., 2003, 125, 8694.

4 J. D. Rinehart, M. Fang, W. J. Evans and J. R. Long, J. Am. Chem. Soc., 2011, 133, 14236.

5 (a) C. A. P. Goodwin, F. Ortu, D. Reta, N. F. Chilton and D. P. Mills, Nature, 2017, 548, 439; (b) F.-S. Guo, B. M. Day, Y.-C. Chen, M.-L. Tong, A. Mansikkamäki and R. A. Layfield, Angew. Chem. Int. Ed., 2017, 56, 11445.

6 D. A. Atwood, The Rare Earth Elements: Fundamentals and Applications, John Wiley and Sons Ltd., 2012.

7 (a) S. Demir, J. M. Zadronsky, M. Nippe and J. R. Long, J. Am. Chem. Soc., 2012, 134, 18546; (b) S. Demir, J. M. Zadronsky and J. R. Long, Chem. - Eur. J., 2014, 20, 9524.

8 J. D. Rinehart and J. R. Long, Chem. Sci., 2011, 2, 2078.

9 (a) L. Ungur and L. F. Chibotaru, Phys. Chem. Chem. Phys., 2011, 13, 20086; (b) N. F. Chilton, C. A. P. Goodwin, D. P. Mills and R. E. P. Winpenny, Chem. Commun., 2015, 51, 101.

10 M. Gregson, N. F. Chilton, A.-M. Ariciu, F. Tuna, I.F. Crowe, W. Lewis, A. J. Blake, D. Collison, E. J. L. Mclnnes, R. E. P. Winpenny and S. T. Liddle, Chem. Sci., 2016, 7, 155.

11 Y.-C. Chen, J.-L. Liu, L. Ungur, J. Lin, Q.-W. Li, L.-F. Wang, Z.-P. Ni, L. F. Chibotaru, X.-M. Chen and M.-L. Tong, J. Am. Chem. Soc., 2016, 138, 2829.

12 J. Liu, Y.-C. Chen, J.-L. Liu, V. Vieru, L. Ungur, J.-H. Jia, L. F. Chibotaru, Y. Lan, W. Wernsdorfer, S. Gao, X.-M. Chen and M.-L. Tong, J. Am. Chem. Soc., 2016, 138, 5441.

13 Y.-S. Ding, N. F. Chilton, R. E. P. Winpenny and Y.-Z. Zheng, Angew. Chem. Int. Ed., 2016, 55, 16071.

14 C. A. P. Goodwin, D. Reta, F. Ortu, N. F. Chilton and D. P. Mills, J. Am. Chem. Soc., 2017, 139, 18714.

15 (a) T. J. Marks and J. R. Kolb, Chem. Rev., 1977, 77, 263; (b) M. Ephritikhine, Chem. Rev., 1997, 97, 2193; (c) V. D. Makhaev, Russ. Chem. Rev., 2000, 69, 727; (d) M. Visseaux and F. Bonnet, Coord. Chem. Rev., 2011, 255, 374.

16 F. Ortu, D. Packer, J. Liu, M. Burton, A. Formanuik and D. P. Mills, J. Organomet. Chem., 2018, 857, 45.

17 F. A. Weber, H. Sitzmann, M. Schultz, C. D. Sofield and R. A. Andersen, Organometallics, 2002, 21, 3139.

18 F. Jaroschik, F. Nief, X.-F. Le Goff and L. Ricard, Organometallics, 2007, 26, 3552.

19 J. C. W. Chien, W.-M. Tsai, M. D. Rausch, J. Am. Chem. Soc., 1991, 113, 8570.

20 F. Jaroschik, F. Nief, X.-F. Le Goff and L. Ricard, Organometallics, 2007, 26, 1123.

21 B. C. Segal and S. J. Lippard, Inorg. Chem., 1978, 17, 844.

22 R. D. Shannon, Acta. Cryst. Sect. A, 1976, 32, 751.

23 A. Abragam and B. Bleaney, Electron Paramagnetic Resonance of Transition Ions, Oxford University Press, 1970.

24 F. Aquilante, J. Autschbach, R. K. Carlson, L. F. Chibotaru, M. G. Delcey, L. De Vico, I. Fernandez Galván, N. Ferré, L. M. Frutos, L. Gagliardi, M. Garavelli, A. Giussani, C. E. Hoyer, G. Manni, H. Lischka, D. Ma, P. Å. Malmqvist, T. Müller, A. Nenov, M. Olivucci, T. B. Pedersen, D. Peng, F. Plasser, B. Pritchard, M. Reiher, I. Rivalta, I. Schapiro, J. Segarra-Martí, M. Stenrup, D. G. Truhlar, L. Ungur, A. Valentini, S. Vancoillie, V. Veryazov, V. P. Vysotskiy, O. Weingart, F. Zapata and R. Lindh, J. Comput. Chem., 2016, 37, 506.

25 L. Ungur and L. F. Chibotaru, Phys. Chem. Chem. Phys., 2011, 13, 20086.

26 (a) J.-L. Liu, Y.-C. Chen and M.-L. Tong, Chem. Soc. Rev., 2018, 47, 2431; (b) S. K. Gupta and R. Murugavel, Chem. Commun., 2018, 54, 3685; (c) Z. Zhu and J. Tang, Geometry and Magnetism of Lanthanide Compounds, in Topics in Organometallic Chemistry, 2018; (d) Y.-S. Meng, S.-D. Jiang, B.-W. Wang and S. Gao, Acc. Chem. Res., 2016, 49, 2381. 